\title{
Impact of National Universities Commission (NUC) Accreditation Exercise on University Administrative Structure
}

\author{
Oribabor, O. A.
}

\begin{abstract}
The study examined the impact of National University Commission (NUC) accreditation exercise on university administrative structure of four selected Nigerian universities between 1995 and 1999. Data were collected through questionnaires administered to 400 staff and 200 students of four Nigerian universities. The universities were; Obafemi Awolowo University Ile-Ife, University of Ibadan, Ibadan, Olabisi Onabanjo University Ago Iwoye, and University of Ado-Ekiti. One hypothesis was generated for the study. The two sets of questionnaires - one for the students and the other for staff were used to elicit information from the respondents. The responses were tested at 0.05 level of significance using chi-square statistics. The study revealed that the accreditation exercise had no impact on administrative structure $\left(X^{2}{ }_{c}=70.30, X^{2}{ }_{t}=12.59, d f=6, p<0.05\right)$ and efficiency of university staff $\left(X^{2}{ }_{c}=35.55 ; X^{2}{ }_{t}=24.99 ; d f=15 ; p<0.05\right)$. Based on the findings of this study, recommendations were made.
\end{abstract}

\section{Introduction}

Nigerian Universities have a common set of NUC prescribed programmes to be implemented by both the academic and administrative staff of the universities. Yet no set criteria were laid down to ensure commonness in the implementation of these prescribed programmes. Even if one were to assume that such criteria exist, no study to our knowledge has investigated such criteria and their adequacy and appropriateness to meet the enthusiastic accreditation process engaged upon by the NUC. It will be recalled that the NUC was set up partly to establish and monitor quality and standard in Nigeria universities. It was however noted that the 
accreditation of the university programmes and subsequent standardization nation-wide by the N.U.C remain substantively superficial especially in the absence of a mechanism to ascertain or ensure that the prescribed programmes are implemented by competent qualified personnel both in the administrative and academic sectors of the university according to laid down criteria. It is possible that the absence of such criteria or lack of such studies is being manifested in the turmoil, militancy and indiscipline prevalent in the universities today. Akinkugbe (1998) at a lecture entitled "University of Ibadan at 50: Time for Paradigm Shift" argued that:

over the past 25 years, dwindling financial resources, student population explosion (with acute accommodation and feeding problems), students vices such as examination malpractices, violence, cultism and rioting, staff and faculty problems have been the lot of the universities.

In an apparent response to these manifestations, a new vocabulary "rationalization" is currently being adopted as a whipping dog or scape goat to the obvious lack of foresight in the accreditation programme. Rationalization should logically have been an integral part of the accreditation process during which standardization not only of academic programme but also of administrative and academic personnel should have also been undertaken. This statement buttressed the fact that Nigerian universities are faced with numerous problems that are capable of undermining the achievement of the purposes for which the universities are established. This makes it more important that the university system needs to be evaluated regularly and more so that the recommendations of the evaluation be put to use.

The Longe Commission (1992) noted that the Federal Government had been well aware of under funding of universities since the late 1970s and had set up various Committees and Commissions to 
examine the problem and make recommendations. The Commission's recommendations led to the setting up by Government the National Implementation Committee on the Review of Higher Education in Nigeria.Adamolekun (1998) however indicated that "the right political atmosphere did not prevail for the commission to conclude its work". One of the positive results of the work of the Committee was the setting up of the Education Tax Fund. So, there is now a source of funds for the restoration of the university system from its present state of near collapse.

The issues of evaluation and accreditation are policy issues. We therefore intend to touch on issues related to the policy process which involves formulation, implementation and evaluation. Liston (1999) for instance, simply sees accreditation as a process of quality assurance. However, the more quality is being pursued to be assured, the more mistakes are discovered and the more the exercise of accreditation is inevitable. Despite this however, the concept still remains poorly understood. He however defines accreditation as a process by which an institution of post secondary education periodically evaluates its own educational activities in whole or in part, and seeks an independent judgment that it substantially achieves its own educational objectives and is generally equal to comparable institutions or specialized units. In this definition, Liston is of the view that for a proper accreditation, there must be:

1. A clear statement of education objectives.

2. A directed self-study focused on these objectives.

3. An on-site evaluation by a selected group of peers.

4. A decision by an independent commission that the institution or specialized unit is worthy of accreditation.

Essentially, the fourth stage of accreditation process of Liston is the NUC accreditation exercise. By and large this stage has been accorded the status of all what accreditation stands for. Institutional accreditation has to incorporate both internal self assessment and 
external judgement. While it is very necessary that there should be certain minimum standards agreed upon and which guide the operations of institutions of similar status nation wide, it is equally desirable that recognition is given to the internal peculiarities of each institution. This idea is reflected in the opinion of Liston (1999) that;

the content and purpose of any set minimum standards, any criteria and any regulations are likely to be of differing value and significance to the different forces, which are conventionally termed stakeholders.

Therefore, the process of accreditation should provide a means of recognizing some levels of performance, quality and integrity which engenders confidence from the public and the broad educational community.

A perceived belief is that accreditation is purported to provide quality assessment which is monitored by bodies assessing quality in post secondary education, including governmental agencies and professional associations. It is also believed that the process of accreditation is undertaken in order to evaluate an institution or programme against some (usually not clearly articulated) minimally acceptable standards which protect the institutions themselves, their students and the public. In this, there are two tensions. Institutions may demand that their diverse and unique character and that of their programme be maintained, despite, and in conjunction with, accreditation process. The second tension arises as government imposes more and more uniformity. For instance, the goals of tertiary education as spelt out in section 6 subsections 45 of the National Policy on Education (2004). The focus of the research was the development of educational raw materials i.e. students from Nigerian Universities to high quality graduates to meet Nigeria's human resources needs. The study involved the interactions that take place between the students, administrative staff and the academic community. This is viewed against the background of standards laid 
down by the National Universities Commission. The survey is limited to the following; Medicine, Arts, Social Sciences, Engineering and Science in the selected Universities.

\section{Statement of the Problem}

In recent times, there has been heightened or increasing concern about higher education due in part to the tension generated by students' unrest and agitation for better conditions of service by university staff in general and incessant strikes. At the core of this tension is the apparent inability of the universities to meet the complex and competing needs of the students, the staff and the society at large. There is therefore the need to examine the impact of NUC Accreditation Exercise on University Administration, hence this study.

\section{Hypothesis}

For this study, a one directional hypothesis was formulated for testing and was stated thus: The N.U.C accreditation exercise has no significant impact on the administrative structure and efficiency of the universities.

\section{Methodology}

The study used a survey research design. The population for the study consisted of staff and graduating students from four Nigeria universities; a purposive random sampling was employed in selecting the four universities, a simple random sampling was used in selecting 400 academic and non-academic staff in the four universities under study. Also, simple random sampling was used in selecting 50 graduating students in each of the four universities, totalling 200 students. Two sets of questionnaires designed by the investigator were employed in data collection. The first questionnaire was tagged Staff Questionnaire and the second one was tagged Student Questionnaire. The two instruments were validated and a cronbach alpha of 0.82 and 0.86 were obtained respectively before they were put to use. 


\section{Results and Discussion}

Results in tables 1 and 2, showed a consistent low number of "yes" responses compared to number of "no" responses to the positive impact of NUC accreditation exercise on administrative structure. Except in OOU, Ago-Iwoye where the number of "yes" responses was higher than the number of "Don't know" responses, the number of "Don't know" responses was also consistently higher than those of "yes" responses in the universities selected. These results indicated that respondents do not see the NUC accreditation exercise as having any impact on administrative structure of their Universities. These results though vary among the three response categories across the four universities, the hypothesis is therefore partly accepted in terms of the impact of NUC accreditation on administrative structure with OAU having "No" response of $67.7 \%$ and "Don't know" of $26 \%$; U.I have "No" of $30.9 \%$ and "Don't know" of 55.7\%; OOU having "No" of $46.9 \%$ and "Don't know" of $14.3 \%$ and UNAD having "No" of $48.0 \%$ and "Don't know" of $30.6 \%$.

A comparison of the proportion of the "positive" response to those of "irrelevant response and "Don't know" response showed that there were few respondents who agreed that the NUC accreditation exercise had impact on the efficiency of staff. The following were the percentages of agreement that the exercise had impact on the efficiency of staff. OAU $13.5 \%$, UI $21.6 \%$, OOU $23.5 \%$, UNAD $24.5 \%$ with an overall percentage of $20.8 \%$ when all the four universities were taken together. There was however a significant difference in the response rates across the six response categories within the four universities $\left(X_{t}^{2}=35.55 ; X^{2}{ }_{t}=24.99=d f=15 ; p \geq\right.$ 0.05). The null hypothesis which stated that the NUC accreditation exercise has no significant impact on the administrative structure and efficiency of university staff is hereby accepted.

This finding was perhaps explainable in terms of the very little response of NUC to the universities even after the accreditation exercise has been carried out. In majority of accreditation exercises, 
areas of need such as physical facilities including laboratory structures and facilities, books, journals and other academic materials are always identified short of expiration however; very little response is made to this area. In a way, this might be responsible for the disproportionate improvement in the impact that such accreditation exercises have on the quality and efficiency of the university staff.

\section{Population of Administrative Staff in Nigerian Universities (1995 - 1999)}

The data presented in table 3 revealed the population of Administrative staff which include administrative and technical staff as well as the secretariat staff for the year 1995 - 1999. The population varied from 45,061 in 1995 to 51,229 in 1998 and then to 47,401 in 1999 with mean of 2072 staff per each university. A minimum of 418 was recorded in 1996, while a maximum of 6320 staff was recorded in one of the universities the same year. However, there was no significant difference in the population of academic staff between 1995 - 1999. ( $\mathrm{F}=0.387$; df $(4,96) ; \mathrm{P} \leq 0.817)$.

\section{Academic / Administrative Staff Ratio}

For the period under review (1995 - 1999), it was found that there was a minimum of four non-academic staff to one academic staff in the Nigerian universities. The number rose to 5 non-academic staff to 1 academic staff in 1996 and 1997. The result is presented in table 4. Figure 1 represents a graphical representation of the population of nonacademic staff in Nigerian universities in the year under study.

\section{Students' / Staff Ratio}

The students / staff ratio ranges between 22 students to one academic staff in 1995 to 25 students per one academic staff in 1996. The ratio of staff to students suddenly reduced to 23 students to one academic staff in 1997 only to rise to 24 students to one academic staff in 1998. Figure 2 shows that to every academic staff, there was four nonacademic staff. The bar represents the corresponding number of nonacademic staff to everyone academic staff. In each case, the number of academic staff is fixed at one. 
This contrasted sharply with the N.U.C recommended studentslecturer ratio (see table 4). The available data on academic staff and students do not show the Faculty breakdown hence the studentslecturer ratio could not be determined for each Faculty. Even then, taking the overall students-lecturer ratio, it was clear from the relevant table (table 5) that it was above the highest recommended ratio for any Faculty during the entire years under study. This corresponds to our findings, through data collected from primary sources as analysed in table 5 that students-lecturer ratio in the universities was too high.

From the picture in table 6 , it was absolutely clear that the maximum ratio of 20 students to one academic staff had not been adhered to. This is not so for students/non-academic staff. The statistics available and presented in table 7 revealed that there were averages of seven students to one non-academic staff for the periods (1995 - 1999). Figure 4 represents a graphical representation of the distribution of students-teacher ratio in Nigerian universities between the periods of 1995 and1999. Each bar stands for the number of students in each year for every one lecturer. The available data revealed that the number of non academic staff in Nigerian universities were more than the number of students admitted into various programmes in each of the years in the periods $(1995-1996)$.

\section{Conclusion and Recommendation}

The N.U.C accreditation exercise had no impact on the administrative structure of Nigeria universities. This may be due to the fact that there is no sound administrative policy and well laid down rules of the administrative duties. This may in fact reflect the lack of regular policy-driven and focused in-service training for administrators. Regular training is more likely to lead to effective and efficient administrative service in the university set up. Once their duties are clearly spelt out, this may not only enlighten the administrators and the university at large, it may also remove the observed disharmony and unnecessary rivalry of the academic staff. This may lead to good relationship between students and administrators. 
Policy matters need to be constantly evaluated and re-evaluated on the basis of inputs from the components of a system for the policy that was formulated. The opinions and attitudes of both academic and administrative members of staff in the university system are needed to re-assess, if necessary, the N.U.C's policy on accreditation. This study is therefore justified within this context.

The study is further justified on the ground that no set criteria were laid down to ensure commonality in both the administrative and academic staff to implement prescribed programme. Even if we assumed that such criteria exist, no study to our knowledge has investigated such criteria and their adequacy and appropriateness to meet the accreditation process embarked upon by the N.U.C.

Finally, there is need for administrators to re-visit their roles and update their manuals by specifying their roles in order to avoid any unforeseen role conflicts as observed from the responses of staff in the study. Further studies could be conducted into how these role conflicts could be prevented within the universities and the role that NUC can play in this regard.

\section{References}

Adamolekun, N.K. (1994): "Higher Education: The Universities". in Akinkugbe, O.O. (Ed) Nigeria and Education; The Challenges Ahead, The Second Obafemi Awolowo Foundation Dialogue, (Ibadan: Spectrum Books, Ltd.).

Ade Ajayi, J.F. (2000): "Towards a Culture of Science and Technology", in A.K. Fashina (e.d), Essays in Science Education, (Ibadan: Sam Bookman Publishers), pp. 1-11.

Ake, C. (1994): Democratization of Disempowerment in Africa, (Lagos: Malthouse Press).

Akinkugbe, O.O. (2001): "The Piper, the Tune and University Autonomy in Nigerian” Social Scientist, Vol. 4, No. 1, pg; 2-6.

Akwukwuma, B.O (2001): Trends in University Administration in Nigeria (2); The Guardian p.48 August 24.

Federal Republic of Nigeria (2004): National Policy on Education (revised) Lagos: Federal Ministry of Education 
Liston, G. (1999): Managing Quality and Standards, Open University Press, Buckingham.

Oghene, J (2003): University Education; Lesson from Britain. The Guardian, p. 77, March 25.

N.U.C (1989): Manual of Accreditation Procedures for Academic Programmes in Nigerian Universities.

(1995): Annual Report, National University Commission, Aja Nwachukwu House, Abuja, Nigeria, pp. 52-55.

(1996): Annual Report, National University Commission, Aja Nwachukwu House, Abuja, Nigeria, pp. 31-34.

(2006): Implication of Remedying the Deficiencies Identified During the Comprehensive Accreditation Exercise. National Universities Commission, Abuja, Nigeria, pp. 19.

Table 1: Impact of NUC Accreditation Exercise on University Administrative Structure

\begin{tabular}{|c|c|c|c|c|c|c|c|c|c|c|}
\hline RESP & UNIVI & SITY & & & & & & & & \\
\hline \multirow{5}{*}{$\begin{array}{l}\text { Don't } \\
\text { Know } \\
\text { No } \\
\text { Yes }\end{array}$} & \multicolumn{2}{|l|}{$\overline{\mathrm{OAU}}$} & \multicolumn{2}{|l|}{ U.I } & \multicolumn{2}{|l|}{$\overline{\mathrm{OOU}}$} & \multicolumn{2}{|c|}{ UNAD } & \multicolumn{2}{|c|}{ TOTAL } \\
\hline & Count & $\%$ & Count & $\%$ & Count & $\%$ & Count & $\%$ & Count & $\%$ \\
\hline & 25 & $26 \%$ & 54 & $55.7 \%$ & 14 & $14.3 \%$ & 30 & $30.6 \%$ & 123 & $31.9 \%$ \\
\hline & 65 & $67.7 \%$ & 30 & $30.9 \%$ & 46 & $46.9 \%$ & 47 & $48.0 \%$ & 188 & $48.3 \%$ \\
\hline & 6 & $6.3 \%$ & 13 & $13.4 \%$ & 38 & $38.8 \%$ & 20 & $20.4 \%$ & 77 & $19.8 \%$ \\
\hline Total & 96 & $100 \%$ & 97 & $100 \%$ & 90 & $100 \%$ & 98 & $100 \%$ & 389 & $100 \%$ \\
\hline
\end{tabular}

$\mathrm{X}_{\mathrm{t}}^{2}=70.30 ; \mathrm{X}_{\mathrm{t}}^{2}=12.59=\mathrm{df}=6 ; \mathrm{p}<0.05$.

Table 2: Impact of the NUC Accreditation Exercise on Efficiency of Administration Staff

\begin{tabular}{|c|c|c|c|c|c|c|c|c|c|c|}
\hline RESPONSE & \multicolumn{10}{|c|}{ UNIVERSITY } \\
\hline \multirow{7}{*}{$\begin{array}{l}\text { Irrelevant response } \\
\text { Don't know } \\
\text { None I know of } \\
\text { Positive impact } \\
\text { Negative Impact } \\
\text { Not applicable }\end{array}$} & \multicolumn{2}{|c|}{$\overline{\mathrm{OAU}}$} & \multicolumn{2}{|c|}{ U.I } & \multicolumn{2}{|c|}{$\mathrm{OOU}$} & \multicolumn{2}{|c|}{ UNAD } & \multicolumn{2}{|c|}{ TOTAL } \\
\hline & 55 & $57.3 \%$ & 40 & $41.2 \%$ & 42 & $42.8 \%$ & 31 & $31.6 \%$ & 168 & $43.2 \%$ \\
\hline & 14 & $14.6 \%$ & 30 & $30.9 \%$ & 24 & $24.5 \%$ & 35 & $35.8 \%$ & 103 & $26.5 \%$ \\
\hline & 14 & $14.6 \%$ & 4 & $4.1 \%$ & 9 & $9.2 \%$ & 7 & $7.1 \%$ & 34 & $8.7 \%$ \\
\hline & 13 & $13.5 \%$ & 21 & $21.7 \%$ & 23 & $23.5 \%$ & 24 & $24.5 \%$ & 81 & $20.8 \%$ \\
\hline & - & - & 2 & $2.1 \%$ & - & - & - & - & 2 & $0.5 \%$ \\
\hline & - & - & - & - & - & - & 1 & $1.0 \%$ & 1 & $0.3 \%$ \\
\hline Total & 96 & $100 \%$ & 97 & $100 \%$ & 98 & $100 \%$ & 98 & $100 \%$ & 389 & $100 \%$ \\
\hline
\end{tabular}

$\mathrm{X}_{\mathrm{t}}^{2}=35.55 ; \mathrm{X}_{\mathrm{t}}^{2}=24.99=\mathrm{df}=15 ; \mathrm{p}<0.05$. 
Table 3: Administrative Staff Population in Nigerian Universities (1995-1999)

\begin{tabular}{||l|l|l|l|l||}
\hline \hline Non-academic staff & & & \\
\hline YEAR & MIN & Max & mean & total \\
\hline 1995 & 491 & 5060 & 2146 & 45061 \\
\hline 1996 & 418 & 6320 & 2058 & 43216 \\
\hline 1997 & 486 & 5351 & 2139 & 44,914 \\
\hline 1998 & 583 & 6026 & 2696 & 28,731 \\
\hline 1999 & 523 & 5114 & 2257 & 47,401 \\
\hline Mean (1995-99) & 418 & 6320 & 2072 & 209323 \\
\hline \hline
\end{tabular}

Source: N.U.C Annual Reports (1995-1999)

Table4: Academic/Administrative Ratio

\begin{tabular}{||l|ll||}
\hline \hline 1995 & $1: 4$ & $(4.18)$ \\
\hline 1996 & $1: 5$ & $(4.68)$ \\
\hline 1997 & $1: 5$ & $(4.38)$ \\
\hline 1998 & $1: 4$ & $(3.67)$ \\
\hline 1999 & $1: 4$ & $(3.73)$ \\
\hline Mean & $1: 4$ & $(4.15)$ \\
\hline \hline
\end{tabular}

Source: N.U.C Annual Reports (1995-1999)

Table 5: N.U.C Recommended Students-Teacher Ratio

\begin{tabular}{|l|l|}
\hline Agriculture & $9: 1$ \\
\hline Science & $10: 1$ \\
\hline Health Sciences / Human Medicine & $6: 1$ \\
\hline Engineering / Technology & $9: 1$ \\
\hline Veterinary Medicine & $6: 1$ \\
\hline Pharmacy & $10: 1$ \\
\hline Environmental Science & $10: 1$ \\
\hline Law & $20: 1$ \\
\hline Social Sciences & $20: 1$ \\
\hline Arts & $20: 1$ \\
\hline
\end{tabular}

Source: N.U.C Annual Reports (1995-1999) 
Table6: Students/Lecturer Ratio

\begin{tabular}{||l|ll||}
\hline \hline 1995 & $22: 1$ & $(21.80)$ \\
\hline 1996 & $25: 1$ & $(25.18)$ \\
\hline 1997 & $23: 1$ & $(22.49)$ \\
\hline 1998 & $22: 1$ & $(21.94)$ \\
\hline 1999 & $24: 1$ & $(23.25)$ \\
\hline Mean & $23: 1$ & $(22.95)$ \\
\hline
\end{tabular}

Table 7: Students/Administrative Staff Ratio

\begin{tabular}{||l|ll||}
\hline \hline 1995 & $5: 1$ & $(5.42)$ \\
\hline 1996 & $8: 1$ & $(7.73)$ \\
\hline 1997 & $7: 1$ & $(6.42)$ \\
\hline 1998 & $7: 1$ & $(7.38)$ \\
\hline 1999 & $7: 1$ & $(6.56)$ \\
\hline Mean & $7: 1$ & $(6.67)$ \\
\hline
\end{tabular}

Source: N.U.C Annual Reports (1995-1999) 
Figure1

POPULATION OF NON-ACADEMIC STAFF IN NIGERIAN UNIVERSITIES (1995-1999)

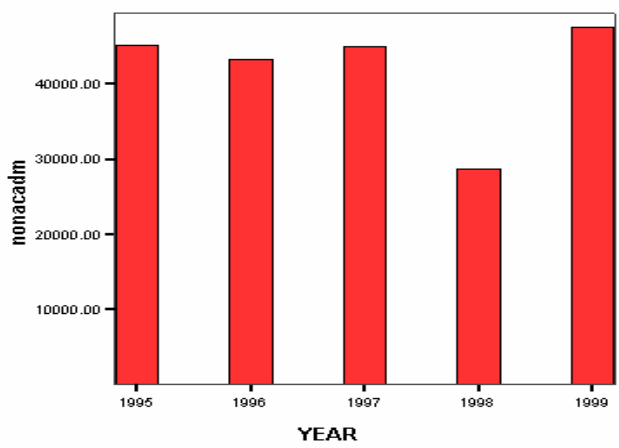

Bars show Sums

Source: N.U.C Annual Reports (1995-1999)

Figure 2

ACADEMIC / NON-ACADEMIC STAFF RATIO IN NIGERIAN UNIVERSITIES (1995-1999)

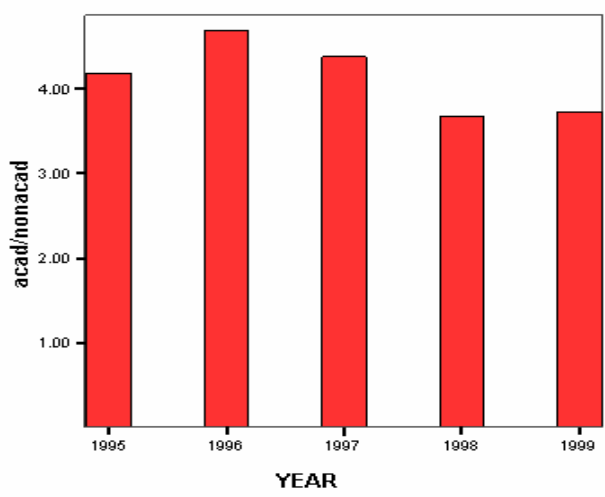

Bars show Means

Source: N.U.C Annual Reports (1995-1999) 
Impact of NUC Accreditation Exercise on University Administrative Structure

Figure 3

STUDENTS- TEACHER RATIO IN NIGERIAN UNIVERSITIES(1995-1999)

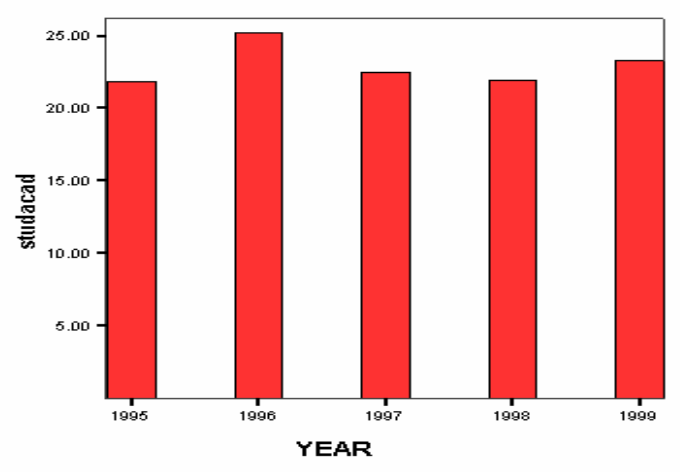

Bars show Means

Source: N.U.C Annual Reports (1995 - 1999)

Figure 4

STUDENTS- NON-ACADEMIC STAFF RATIO IN NIGERIAN UNIVERSITIES(1995-1999)

Sour

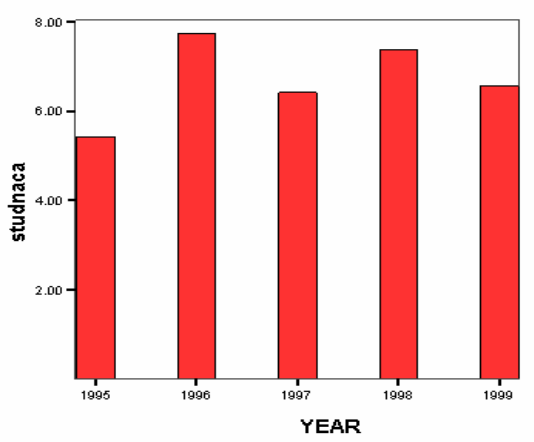

Bars show Means 